\title{
The Treatment of Inguinal Hernia in the Elderly: Always Local?
}

\author{
Salih Tosun, Oktay Yener*, Ozgur Ekinci and Mehmet Zeki Buldanlı \\ Istanbul Medeniyet University Goztepe Education and Research Hospital, Department of General Surgery, Turkey
}

Submission: September 01, 2016 ; Published: September 23, 2016

*Corresponding author: Oktay Yener, Istanbul Medeniyet University Goztepe Education and Research Hospital, Department of General Surgery, Istanbul, Turkey, Tel:05337088469; Email: oktayener@gmail.com

Abstract

Abstract: Inguinal hernia is one of the most common diseases in the elderly. Local anaesthesia (LA) is almost used in open inguinal hernia surgery; whereas in routine practice, regional anaesthesia (RA) or general anaesthesia (GA) is the method of choice in the elderly.

Methods: A retrospective analysis of all inguinal hernia repairs performed in our hospital over a 3-year period was performed. The outcome measures were type of anaesthesia used, patient demography, co-morbidities, hernia type, hernia repair methods and hospital stay. Those who threated by local anaesthesia, recurrent and bilateral hernias and ASA (American Society of Anesthesiologists) grade IV patients were excluded from the study.

Results: A total of 237 hernia repairs were performed during the study period. According to the ASA classification; 130 patients were grade I, 98 were grade II and 9 were grade III. Of these 153 (\%64.5) repairs were performed under RA and 84 (\%35.5) under GA. Average hospital stay was 1.05 /day. There was no mortality.

Conclusion: There are no major differences in patient recovery after LA, RA or GA hernia repair in ASA I, II and even in ASA III. Especially elderly patients should be offered a choice of anaesthesia for repair of their inguinal hernia.

\section{Background}

Inguinal hernias are common in the elderly because of the loss of strength of the abdominal wall and conditions with increased intra abdominal pressure [1,2]. The demand for surgical services for inguinal hernia is increasing due to the increase of an ageing population and hernioplasty gives these patients a remarkable improvement of quality of life [3-5]. Hernioplasty in primary election can always take advantage of local anaesthesia [6], dispite relative complications such as poor patient, morbid obesity, and bilateral hernioplasty, bulky and recurrent inguinal hernias [7].

However elderly patients have complex medical problems to make them unsuitable for day-case rates repair. Patients with co-existing illness and poor ASA grades III, IV are often excluded in randomized studies when comparing day case rates and different anaesthetic techniques [8,9]. The objective of this study was to look at the safety of inguinal hernia repair for older patients (aged 65 and more), in terms of unplanned admission, morbidity, mortality with regional or general anaesthesia.

\section{Methods}

We performed a retrospective review of all inguinal repairs performed between January 2010 and December 2012 in our unit by using our hospitals audit module of a computerized patient information system (SARUS internet and auto motion system). The data were collected retrospectively by case-note review and included demographics, hospital stay, ASA grade, technique of repair, early morbidity and mortality. The patients were grouped into different ASA grades prior to surgery based on the co-morbidity of the patient. All patients had to undergo further anaesthetic assessment prior to surgery. Exclusion criteria were: age less than 65 years, ASA grade IV, recurrent hernia, bilateral hernia, laparoscopic repairs and LA repairs. Poor patient status, obesity, bulky inguinal hernia and even systemic malignancy were not exclusion criteria. The patients were grouped according to Nyhus classification for hernia type and repair techniques.

\section{Results}

A total of 237 patients underwent inguinal hernia repair during the study period. The median age of the geriatric patients were 72 (range, 66-93). Of the study group, 153 (\% 64.5) patients underwent surgery under RA and 84 (\%35.5) patients under GA. The patient's characteristics and anesthetic technique are summarized in (Table 1). The majority of the patients were ASA grade I and II (\% 96.2) with ASA grade 3 
patients accounting for $\% 3.8$ of all patients (Table 2). According to the Nyhus classification, 124 patients were type II, 96 type III a, 11 type III b and 6 type III c (Table 3). Treatment was 158 with mesh techniques (Lichtenstein and mesh plug), 79 with suture technique (modified Bassini) (Table 1). Although most of the patients were successfully discharged next day, only 9 of them required the other day because of hematoma, seroma and scrotal edema. Hospitalization rate was 1.07 /day. There were no deaths or major complications in the group. Mean operation time was $46 \mathrm{~min}$ (32-105 $\mathrm{min}$ ) in the general anesthesia group. Mean operation time was $65 \mathrm{~min}$ (40-135 $\mathrm{min}$ ) in the general anesthesia group.

Table 1: Patients characteristics.

\begin{tabular}{|c|c|}
\hline \multicolumn{2}{|c|}{ Sex } \\
\hline Female & $10(4.3 \%)$ \\
\hline Male & $227(95.7 \%)$ \\
\hline Age in years median & $72.2($ range,66-91) \\
\hline \multicolumn{2}{|c|}{ Anaesthesia type } \\
\hline Regional & $153(64.6 \%)$ \\
\hline General & $158(65.4 \%)$ \\
\hline Technique & $79(33.4 \%)$ \\
\hline Mesh techniques & $1.05($ range,1-2) \\
\hline Suture technique & $98(41.35 \%)$ \\
\hline Mean hospital stay & $9(3.79 \%)$ \\
\hline \multicolumn{2}{|c|}{ Comorbidity } \\
\hline Benign & $107(45.14 \%)$ \\
\hline Totign &
\end{tabular}

Table 2: ASA classification of the patients.

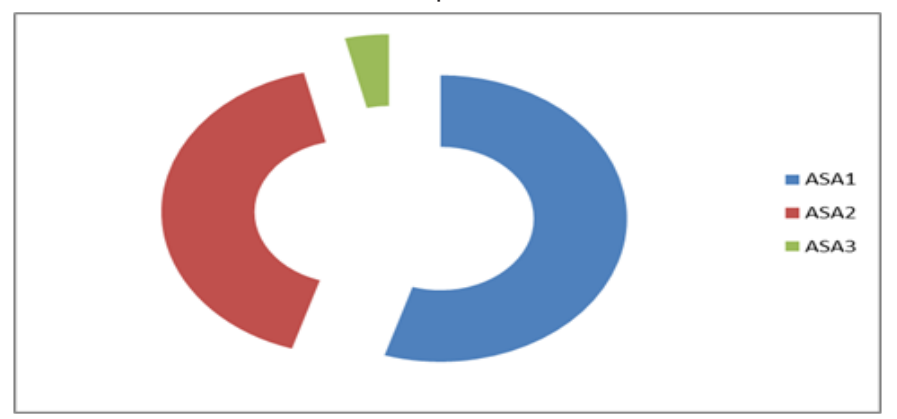

Table 3: Nyhus Classification of the patients.

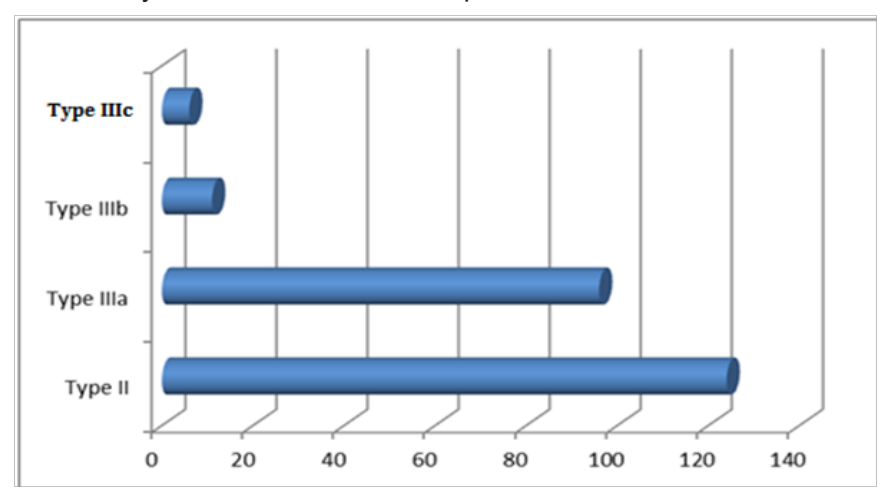

\section{Discussion}

Surgeons sometimes may be reluctant to perform elective repair of a hernia, because of the increased risk of postoperative complications in elderly patients. However, delay may increase the possibility of strangülation which necessitates surgery under advers conditions, and on increased risk of morbidity and mortality [10-13]. In geriatric patients, the anesthetic technique used has great importance because of the complications after the surgery. Elective open inguinal hernia repair under LA in a daycase treatment has a good outcome also in the elderly $[14,15]$. However, geriatric patients have complex medical problems increasing the risk of surgery and make them unsuitable for daycase repair [16].

Commonly perceived problem of LA inguinal hernia repair is the pain of infiltration. This can be extreme enough for patients to be dissatisfied with the procedure [17]. Another potential problem of LA inguinal hernia repair is toxicity especially in bilateral hernioplasty and obese patients who require large volumes. Also LA employment is another problem in recurrent and bulgy hernias. LA employment consists of several phases; first percutaneos, then incisional that is exclusively of surgical pertinence, as it is the task of the surgeon to identify the points of landmarks, locate and infiltrate properly [18]. Then, there must be a pretrial training for the surgeons in which taught to do the LA technique in a standardized manner. Conversion to GA seems to be the other problem. Some patients change their mind in the anesthetic room and request a general anesthetic, some show anxiety during the process and those patients had to undergo further anesthetic assessment.

We must talk more about Tailored Surgery, the so called personalized surgery, individualized, and built on the needs and characteristics of the patient [19]. The concept of Tailored Surgery encompasses not only technical-surgical and prosthetic choices but also anesthetic (local, assisted local, spinal or loco regional, general). In the elderly, affected by multiple pathologies in ASA IV group is better to perform the open technique in LA. The shortness of the hospitalization may be less necessary in the elderly and the elderly patient may not have a necessity for a rapid renewal of hard work or sport. In our study, LA is being offered to higher risk groups including ASA IV. ASA III patients underwent surgery with RA. Most of the patients were successfully discharged next day except 9 and mean hospitalization rate was 1.07 days that seems expectable.

Mortality after elective hernia is sufficiently low that it is not possible assesses differences using LA, GA or RA in a clinical trial setting [20]. Claims, therefore, that one type of anaesthesia is safer than another are unfounded and should not influence decision making in the medically fit patient with inguinal hernia. In our study there was no mortality or major systemic complications. Surgeons of varying backgrounds and experience participated in our trial. Moreover, surgeons were free to use their preferred method of hernia repair so that conditions in our 
trial matched those, in general surgical practice.

Our study demonstrates that geriatric patients requiring inguinal hernia repair shouldn't be avoided from the GA or RA in terms of Tailored Surgery. Elderly patients with inguinal hernia can be safely treated in open surgery under RA or GA with good preoperative anesthetic assessment and patient selection. Sure we don't say that inguinal hernia must be performed under GA or RA. LA seems to be the first choice in the open inguinal hernia repair also in the elderly. We think that decision to use one or the other should be at the discretion of the individual surgeon in consultation with the patient.

\section{Conclusion}

With good preoperative assessment and patient selection, elderly patients without significant co-morbidities can be safely treated with general or regional anaesthesia as well as local anaesthesia by using open hernia techniques.

\section{References}

1. Wagh PV, Leverick AP, Sun CN, White HJ, Read RC (1974) Direct inguinal herniation in men: a disease of collagen. J Surg Res 17(6): 425-433.

2. Peacock EE (1984) Internal reconstruction of the pelvic floor for recurrent groin hernia. Ann Surg 200(3): 321-327.

3. Turrentine FE, Wang H, Simpson VB, Jones RS (2006) Surgical risk factors, morbidity, and mortality in elderly patients. J Am Coll Surg 203(6): 865-877.

4. Patti R, Aiello P, Di Vita G (2011) Improvement of quality of life in elderly after inguinal hernioplasty. In Part of the Supplement: XXII Annual Meeting of the Italian Society of Geriatric Surgery. BMC Geriatrics 11(1): 44.

5. Zieren J, Zieren HU, Wenger F, Muller JM (2000) Repair of inguinal hernia in elderly. Results of the plug-and-patch repair with special reference to quality of life. Chirurg 71(5): 564-567.

6. Simons MP, Aufenacker T, Bay-Nielsen M, Bouillot JL, Campanelli G, et al. (2009) European Hernia society guidelines on the treatment of inguinal hernia in adult patients. Hernia 13(4): 343-403.
7. Kehlet H, White $P$ (2001) Optimizing Anesthesia for inguinal Herniorrhaphy: General, Regional, or Local Anesthesia? Anesth Analg 93(6): 1367-1369.

8. The MRC Laparoscopic Groin Hernia Trial Group (1999) Laparoscopy versus open repair of groin hernia: a randomised comparison. Lancet 354(9174): 185-190.

9. Wellwood J, Sculpher MJ, Stoker D, Nicholls GJ, Geddes C, et al. (1998) Randomised controlled trial of laparoscopic versus open mesh repair for inguinal hernias. BMJ 317: 103-110.

10. Rosenthal RA (1994) Small-bowel disorders and abdominal wall hernia in the elderly patient. Surg Clin North Am 74(2): 261-291.

11. Tinmald GR. CooDerman M (1982) Inguinal and femoral hernia repair in geriatric batients. Surg Gynecol Obstet 154(5): 704-706.

12. Nehme AE (1983) Groin hernias in elderly patients. Management and prognosis. Am J Surg 146(2): 257-260.

13. Brittenden J, Heys SD, Eremin 0 (1991) Femoral hernia: mortality and morbidity following elective and emergency surgery. J R Coll Surg Edinb 36(2): 86-88.

14. Sanjay P, Leaver H, Shaikh I, Woodward A (2011) Lichtenstein hernia repair under different anaesthetic techniques with special emphasis on outcomes in older people. Australas J Ageing 30(2): 93-97.

15. Nienhuijs SW, Remijn EEG, Rosman C (2005) Hernia repair in elderly patients under unmonitored local anaesthesia is feasible. Hernia $9(3)$ : 218-222.

16. Gianetta E, de Cian F, Cuneo S, Friedman D, Vitale B, et al. (1997) Hernia repair in elderly patients. Br J Surg 84(7): 983-985.

17. Callesen T, Bech K, Nielsen R, Anderson J, Hesselfeldt P, et al. (1998) Pain after groin repair. Br J Surg 85(10): 1412-1414.

18. Compagna R, Vigliotti G, Coretti G, Amato M, Aprea G, et al. (2012) Comparative study between Levobupivacaine and Bupivacaine for hernia surgery in the elderly. BMC Surg 12(1): S12.

19. Hübner M, Schäfer M, Raiss H, Demartines N, Vuilleumier H (2011) A tailored approach for the treatment of indirect inguinal hernia in adults-an old problem rivisited. Langenbecks Arch Surg 396(2): 187192.

20. Haapaniemi S, Sandblom G, Nilsson E (1999) Mortality after elective and emergency surgery for inguinal and femoral hernia. Hernia 3(4): 205-208.

\section{Your next submission with JuniperPublishers} will reach you the below assets

- Quality Editorial service

- Swift Peer Review

- Reprints availability

- E-prints Service

- Manuscript Podcast for convenient understanding

- Global attainment for your research

- Manuscript accessibility in different formats

(Pdf, E-pub, Full Text, audio)

- Unceasing customer service

- Track the below URL for one-step submission

http://juniperpublishers.com/online-submission.php 